\title{
ICT-Based Instruction Amid Covid-19: The Case Study of Faculty of Sciences and Technologies, Tangier (FSTT)
}

\author{
Correspondence: $\quad$ Bachiri Housseine Assistant Professor, Faculty of Sciences and Technologies (FSTT), \\ <Housseinebachiri87@gmail.com> Abdelmalek Essaâdi University in Tangier
}

\begin{abstract}
This paper contextually endeavors to grant insights and perceptions on the teaching of English for Specific purposes (ESP) through ICT based instruction amid COVID-19 at the Faculty of Sciences and Technologies in Tangier (FSTT). To avoid total curriculum disruption, the FSTT urgently declares online learning, which has palpably manifested a plethora of pitfalls primarily pertinent to logistics according to the study results. Drawing on previously published materials, the use of quantitative research analysis allows the researcher to empirically unravel different challenges and educational gaps among the research population. The findings of the survey indicate that more investment should be made at the level of research in order to enable ICT- based instruction to be more regulated, yet most importantly properly managed. By so doing, students' motivation and interaction tremendously augment as they become more genuinely and actively engaged in the teaching/learning process.
\end{abstract}

Keywords: ICT-based instruction, Insights and perceptions, Challenges, Higher education

\section{Introduction}

After the sudden closure of schools and research centers due to Coronavirus infection worldwide, Morocco has decided to embrace distance education. This decision has unanimously been endorsed by the Ministry of National Education and Vocational Training (Ministry of Education 2020), combined with a strong endorsement of the Moroccan Parliament and the House of Representatives. The shift toward distance education is meant to successfully finish the academic year without disruption or delay. This new learning paradigm has set new educational rules and goals, especially with respect to teaching materials, in-class activities, pedagogy, and assessment in order to accommodate different students' learning styles and multiple intelligences. In effect, distance education has evolved with the constant development of means of communication around the world, and considerably witnessed quantum leaps with the emergence of modern social media and the development of the internet in the last two decades. This has continuously triumphed the role of ICTs in distance education, without which e-learning becomes inapplicable or rather non-existent.

A few days before the start of the new school year 2020/2021, the country's Ministry of National Education decided to adopt "distance education" as an educational gateway, while providing face-to-face education to students refusing to follow virtual instruction. This ministerial decision comes in light of the increasing exacerbation of the epidemiological situation in Morocco in recent weeks, and the registration of mounting numbers of new infected victims of COVID-19. Following worldwide statistics and most reliable news channels' guidelines, one can stress that distance education is no longer perceived as a luxury, entertainment, or a supplementary pedagogical tool in which students virtually spend time with their teachers. Today, especially after the disruption of educational systems in most countries of the world, distance education is no longer an addition. It is rather a reality and responsibility that has become clearly embodied and imposed by the present facts across the globe.

Information and Communication Technology (ICT) has received a global concern for its usefulness and enormous effectiveness in shifting education to an advanced level. Many studies have proven that the use of ICT in education is becoming the backbone of any education system as it plays a decisive role in changing the classroom dynamics; it is no more a one-way based instruction, but a twoway based communication in which teachers and students interact in a more stimulating environment where students should make use of their metacognitive skills, such as problem solving, critical thinking, and way of reasoning (Gardiner, 1993; Davis \& Shade, 1999; Jung, 2005; Hew \& Brush, 2007; Soussi, 2015; Bachiri \& Tribak, 2020).

\subsection{Research Questions}

This study aspires to answer the following questions:

- What makes ICT-based instruction's implementation difficult?

- Do students prefer ICT-based instruction in lieu of face-to-face teaching?

- How can technology integration into teaching be more fruitful?

\section{Literature Review}

There is no doubt that Information and Communication Technologies (ICTs) have become commonplace entities in all aspects of life. Kopinska (2013) believes that Technologies are rapidly gaining the attention and interest of teachers and learners in EFL classrooms worldwide. For Daniels (2002), ICTs have become, within a very short time, one of the basic building blocks of modern society. Many

countries consider mastering the basic skills and concepts of ICT is fundamentally core to creating a modern education system. It is needless to say that modern technology unquestionably offers plenty of tools that can be used in classrooms to improve teaching and learning quality (Bruniges, 2003; Lefebvre \& Bingimlas, 2009; Hamidi, Meshkat, Rezaee \& Jafari 2011; Hussain, Morgan \& AlJumeily, 2011).

Globalization has unequivocally revolutionized the world in myriad ways. The Moroccan education system is no exception. It has witnessed a variety of remarkable reforms, particularly in terms of incremental development in technology and communications. This has certainly led to a growing information-oriented community among different education actors, be they policy makers, curricula designers, teachers and/or students. The implementation of ICT is not new to the Moroccan education system as several bold attempts were already 
made by Moroccan educationalists in the late 1990s (Ennaji, 1998). In a paper presented at the 18th Moroccan Association of Teachers of English conference (MATE) in 1998, Ennaji advocates the use of new technologies in English language teaching and explains its merits for both educators and learners. Since then, many initiatives have continuously been undertaken so as to instill and promote the utilization of ICTs in education and making open-source software available for all users. For instance, the Computer Assisted Teacher Training (CATT) in 1999, the Moroccan Virtual Campus (MVC) in 2002, the Morocco Wide Area Network (MARWAN Project) in 2002, GENIE Program in 2005, NAFIDA Project in 2008, INJAZ Project in 2009, ITQANE Project in 2010, and LAWHATI Program in 2015.

All these diverse programs have specifically been designed to accomplish one ultimate goal that is to contribute to the development of the national educational system and promote the culture of information technology. Furthermore, "Maroc Numeric 2013" is a program developed as part of the government's National Strategy for Information Society and Digital Economy. Among the strategic priorities of "Maroc Numeric 2013" is to create educational content platforms (ITU 2012), generalize information and communication technology in Moroccan universities, modernize the higher education system, and increase the quality of training among both students and teachers.

Kirkwood (2008) investigates how undergraduate learners use online resources. He finds that most learners use the internet for "personal, domestic, social and employment purposes as well as for educational goals" (p. 381), but seeking information resources is most frequent when it is directly useful for their ongoing studies, particularly in relation with assessment. In this regard, it is important to mention the strategic role of information and communication technologies in a prime mover toward the attainment of the 2030 Sustainable Development Goal 4 of the United Nations (UN), which seeks to "ensure inclusive and equitable quality education and promote lifelong learning opportunities for all" (p. 19-20).

Serious debates are increasingly sparked about re-thinking and re-designing the future of distance education after COVID-19. Hence, while evaluating the digitalization of higher education during this period, a number of pertinent facts evoked, specifically in terms of students' and teachers' digital competence and availability of information on online learning (Olasile \& Emrah, 2020). Some of them are digital natives, yet others do not have the necessary skills. In the same vein, Bachiri and Sahli (2020) conducted a quantitative and qualitative study examining distance learning in the EFL instruction in Morocco in the wake of COVID-19.

According to them, "distance learning is still making 'baby steps', in Morocco, as it is faced with numerous structural problems ranging from infrastructure and pedagogy to content and evaluation" (p. 255). Both Bachiri and Sahli insist on the reinforcement of infrastructure and quality teacher training so as to meet students' needs and reduce digital illiteracy among EFL practitioners. It goes without saying that the use of ICTs in education is very fruitful and enriching in many ways; yet there are many educators, policy and decision makers who argue that the use of ICTs is time consuming, costly to implement, can even be difficult to use and the benefits can remain unclear and doubtful. The way educators, teachers and professionals understand the need of ICT application in educational process depends on many factors. ICT alone cannot improve teaching; rather it is the ways in which ICT is employed in the different learning activities that is of crucial importance (John \& Sutherland, 2004). This will depend on the teacher and their pedagogical predisposition in delivering content knowledge to students.

It must be noted that teachers' readiness plays an integral part in the implementation and continuity of distance education. For Hutchison and Reinking (2011), a lack of specific knowledge about technology and how to combine it with the existing pedagogical content knowledge might be inefficient to support students' learning. According to Berner (2003), and Summers (1990) as cited in Bordbar (2010), teachers' computer competence is a major predictor of integrating ICT in teaching. Evidence shows that the majority of teachers who show negative or neutral attitudes toward the integration of ICT into teaching and learning processes lacked knowledge and skills that would allow them to make "informed decision" (Al-Oteawi, 2002, p. 253 as cited in Bordbar, 2010). Pelgrum holds a similar view (2001), in which he contends that the success of educational innovations largely depends on the skills and knowledge of teachers.

Additionally, he finds that teachers' lack of knowledge and skills is the second most inhibiting obstacle to the use of computers in schools. Demirci (2009) conducted a study on teachers' attitudes towards the use of Geographic Information Systems (GIS) in Turkey.

The study revealed that though barriers, such as lack of hardware and software, teachers' positive attitudes toward GIS was a fundamental determinant to the successful integration of GIS into Geography lessons. Likewise, Knezek and Christensen (2000) hypothesized that high levels of attitude, skill and knowledge proficiency, and tools (level of access) would produce higher levels of technology integration that will be positively reflected upon students' achievements. In their survey, Berge and Muilenburg (2000) identified 10 main barriers to distance education:

- Increased time commitment

- Lack of money to implement distance education programs

- Organizational resistance to change

- Lack of shared vision for distance education in the organization

- Lack of staff support to help course development

- Lack of strategic planning for distance education

- Slow pace of implementation

- Faculty compensation/incentives

- Difficulty keeping up with technological changes

- Lack of technology-enhanced classrooms, labs, or infrastructure

In a nutshell, positive attitudes often encourage less technologically skilled teachers to learn the skills necessary for the implementation of technology-based activities in the classroom.

El-Houssaine (2015), carries out quantitative research, about the adoption of technology in Moroccan classrooms, via online distribution of one hundred questionnaires to students in different Moroccan cities. In summarizing his findings, the author mentions that:

According to the data collected from the answers of the respondents, the great percentage of students want, choose, or prefer software to be used communicatively. For example, being familiar with virtual games shows the interaction and the communication of students with the software that allows them to be more involved, have fun, and be selfmotivated to play" (n/a).

The web environment permits teachers, professors and students to search through a gazillion of files around the world within a few minutes or less to locate and access authentic materials (e.g., newspapers, magazines, articles, journal papers, videos, movies, movie reviews, and so forth). They can also use the web to publish and share texts or multimedia materials with classmates or with the general public. ICTs have the ability to accelerate, empower, and deepen skills, to motivate and engage students, to help relate school experience to work practices, create economic viability for tomorrow's workers, as well as strengthening teaching and helping schools change (Davis \& Tearle, 1999; Lemke \& Coughlin, 1998; cited by Yusuf, 2005). 


\section{Methodology}

\subsection{Instrumentation}

The current study is quantitative in nature. The impetus behind the use of statistical data is to include large participation of students at the FSTT. The questionnaire was divided into three main sections:

- Personal information

- Insights and perceptions on ICT-based instruction

- Challenges

The questions written in the aforementioned data collection method incorporated both close- and open-ended questions (toward the end of the questionnaire) that essentially revolved around the issue investigated at hand. The questionnaire was administered online through Google Forms. Data collection occurred between the months of February and first week of March 2021.

To guarantee maximum face validity, a pilot study was conducted in order to assess the feasibility, soundness, and relevance of the questionnaire's content. The questionnaire was in the first instance shared with 5 English teachers in order to underline or highlight any questions that were redundant, obscure or unclear. In the same manner, the aforementioned teachers were instructed to provide feedback about the form and content of the questionnaire. Once the pilot test came to an end, the researcher modified the questionnaire as instructed.

\subsection{Population of the study}

The research participants taking part in this study were $1^{\text {st }}$ year Master students at the FSTT, majoring in two different academic disciplines (Computer Science and Coastal Sciences: Multidisciplinary Approach). The aforementioned students were the ones that the researcher mentored for a whole semester. The population generally share the same characteristics, such as the language of instruction, education level and semester number. Male participants constitute 58.2\% while female ones constitute $41.8 \%$, making the participation of males slightly higher than that of females. Participation was entirely optional. Gender is not an issue in this particular study. The age of participants ranges between 20 and 26 years old. The link of the questionnaire was sent to participants' personal and institutional email addresses. Follow-ups were also done to ensure the participation of all students in the previously mentioned Masters.

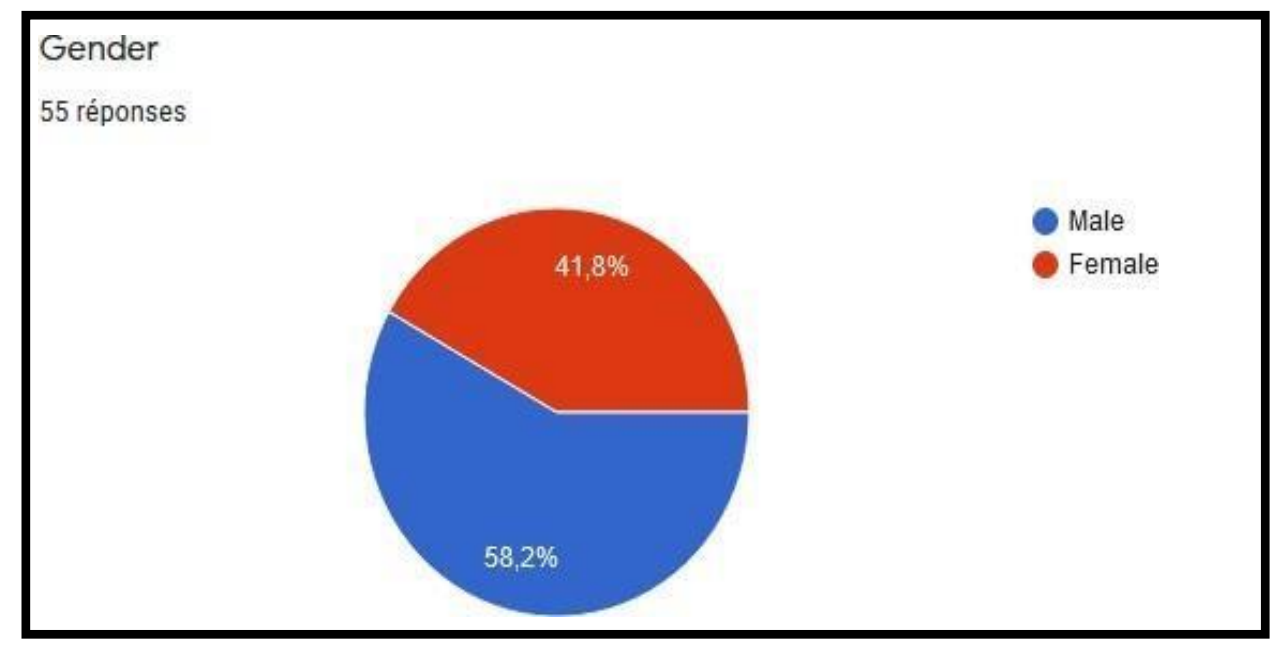

Figure 1: Participants' gender

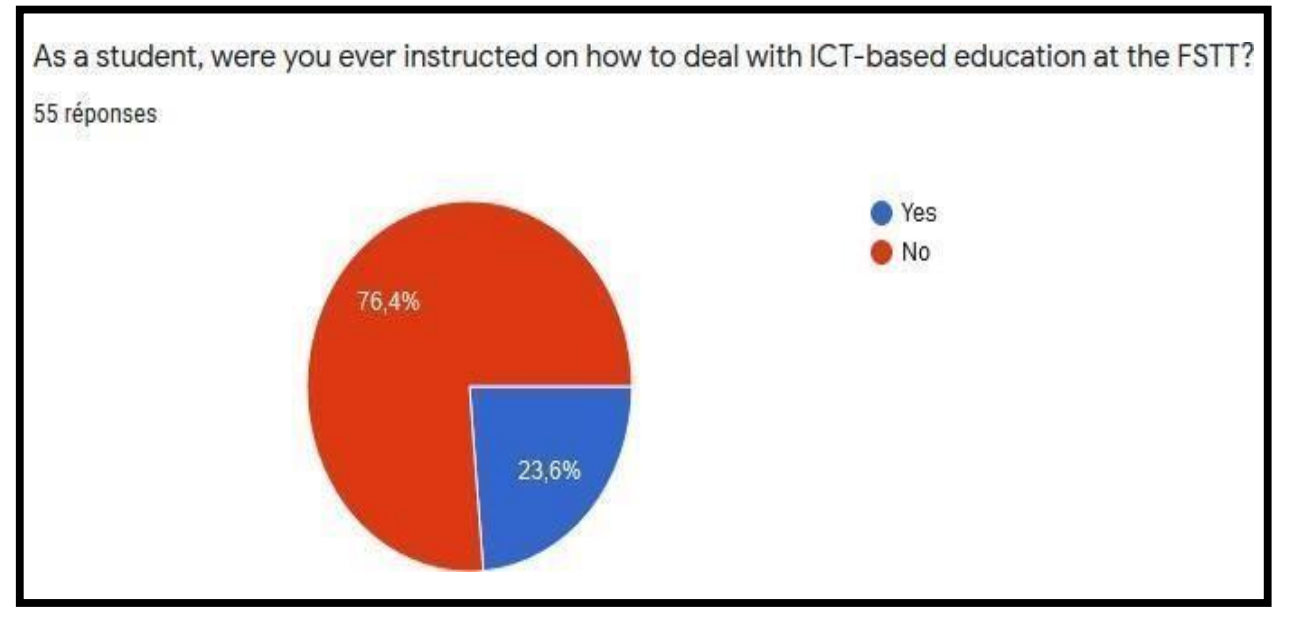

Figure 2. Prior instruction on ICT-based education at the FSTT

\section{Data Analysis}

It is surprising from the chart above that $76,4 \%$ of the participants responded to this question in the negative. In fact, this is not the case of the FSTT's students only, but it is the case of the majority of Moroccan university students, including instructors and education practitioners who received no or very little training on how to implement ICT in the teaching/learning process. In effect, research has made it clear that effective ICT skills training and convenient employment in classroom practices is mandatory and decisive to cope up with the new trends of the era, as well as to measure up to the requirements of a successful instruction. It is needless to mention the benefits and the key role ICTs perform in the promotion and enhancement of education. ICTs have changed the conception of education over the globe. Their creditworthy and weigh in the process is highly recognized because not only they pertinently keep students and their teachers on the same track with the same objectives in mind, but they have also demonstrated to be cost- effective. It is so because an appropriate use of technologies in education has proven to save time, energy, and money, especially for remote teachers and students who are obliged to travel to be on university campus.

However, one cannot turn a blind eye on the different challenges and difficulties that students encounter in education technology integration. Students lack productive training on how to incorporate ICT in their studies. To tell the truth, education governors discard the significance of ICT training and the vital role it plays in course delivery and interaction. This, in turn, triggers hostility toward the take up of technology in course instruction. Students with no previous exposure to Information and Communication Technologies do not feel they are in their comfort zone. This situation may cause embarrassment and intimidation when using ICTs in Class. Insecurity and lack of selfconfidence initiated by the dearth of congruous training are the most emerging impediments that may hinder a smooth and effective 
integration of ICT in education. Thereby, barriers to a proper ICT integration in education are believed to be due to the scarcity of quality training available for both students and teachers.

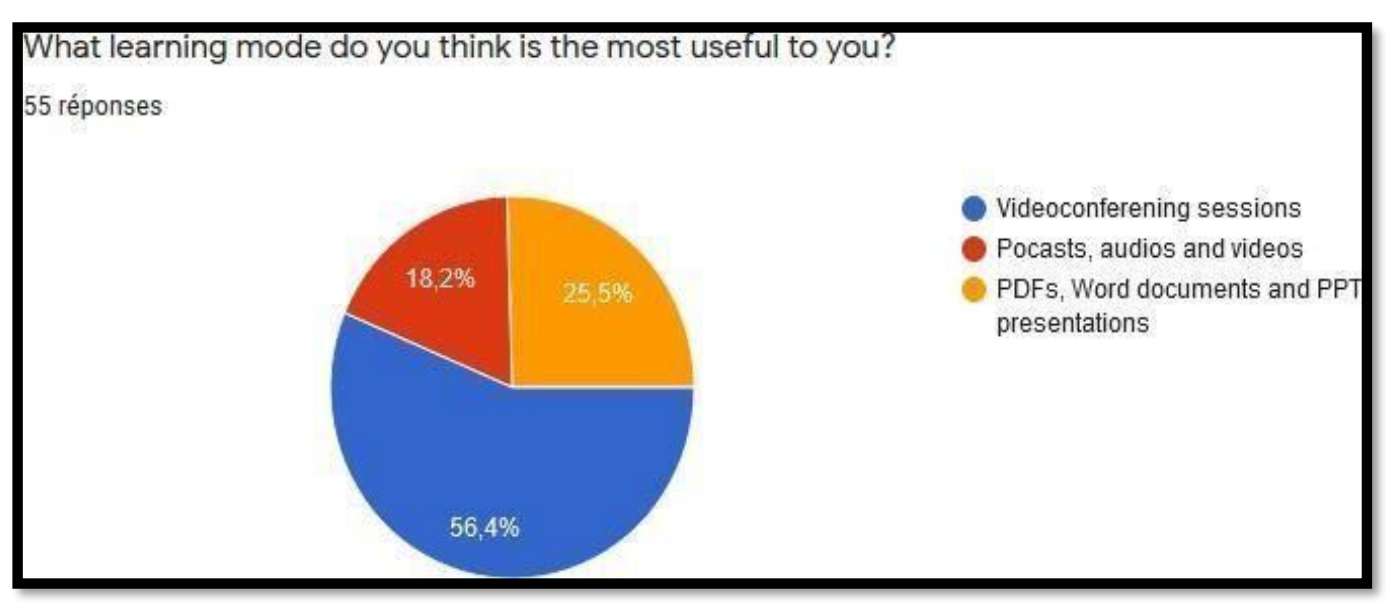

Figure 3: ICT learning mode

Based on the percentages received, it is quite striking that videoconferencing sessions receive $56.4 \%$. Such a percentage is very revealing of the importance of immediate and direct interaction via online platforms, which shows a great tendency toward the employment of technology in the teaching/learning process, especially when courses are delivered via visual aids. In actuality, it has been proven that the implementation of visual aids in education is regarded to be a powerful driving force toward an effective and engaging learning. Technology integration in the current millennium has become indispensable, particularly in the wake of COVID19. Students who are exposed to an interactive learning through a plethora of visual aids tend to reinforce their creativity and imagination, as the central role of visual-based instruction is to tap on learners' intelligences and critical thinking to bring out the best of them. Both teachers and students can work on issues and discuss topic simultaneously with the availability of a good internet connection. This will allow more verbal and non-verbal communication to happen in a synchronous mode. Learning can take place in the form of presentations, readings, dialogues, debates, discussions, and so forth. One issue that could rise in this line of thinking is classroom management where students could want to enthusiastically participate at the same time, and this perhaps creates a bit of noise and disorganization. But if the instructor mutes all participants on any given online platform, he/she could manage to run the session successfully. Written documents in all their forms and magnitude (PDFs, Word documents, and PPT presentations) form 25,5\%, which is indicative of the fact that ICT-based instruction and traditional teaching are nearly similar in course preparation, yet they differ in delivery and assessment. In ICT-based instruction, teachers make sure to send course materials beforehand in order to give students an opportunity to read, research, and reflect upon the material that will be dealt with in class. This way students will be able to enrich and interact with written and visual documents seamlessly and effectively. Additionally, this mode of pedagogy is expressive of autonomous learning where students find themselves trying to make sense of written materials alone, which encourages self- reliance in learning and knowledge discovery. It will also be manageable for students to incrementally digest course content when reading is done at home and exercises are done at the time of class session (blended learning). This mode of learning makes students feel more comfortable and reassured since they learn on their own pace, and information can be obtained in a more consistent and congenial manner. Multimedia-based course content (Podcasts, audios and videos) were ranked last with a percentage of $18,2 \%$. This is fathomable as the current educational context is struck with one of the greatest pandemics of all time, COVID-19. Teachers would download educational videos and audios, as well as record themselves, and send the latter to students to interact with in written, spoken, and visual formats. In actuality, multimedia-based content is deemed to be the main pillar of ICT-based education. Therefore, a careful and satisfactory amount of course preparation is highly recommended on the part of teachers.

3) Please, describe any challenges you faced while experiencing ICT-based education in this semester?

This open-ended question was asked in order to disclose, if any, the challenges that students face in ICT-based instruction. Since this was an entirely new experience, the majority of research participants complained about lack of technical support, a good internet speed and motivation.

It is believed that lack of technical support and maintenance is deemed to be the primary problem in integrating ICT into classrooms. In an increasingly digitized world, student success is becoming more and more measured by the ability to effectively utilize computer technology. Therefore, providing technical assistance to students can be of great help to them to learn more and reach higher.

Additionally, a good internet connection can have a direct impact on students' motivation, and this problem has largely prevailed in virtual education during the COVID-19 era where both students and educators complain about the low internet frequency in which their online courses get disrupted. This online disruption can potentially slow down or rather break down the learning process. As a result, students' motivation decreases over time, and hence half- hearted participation starts taking place. In fact, motivation plays an integral part in online learning, and teachers ought to create stimulating course content and activities that fuel students' creativity and imagination. When students are motivated, they develop a more sense of belonging toward their learning. The more motivated they are, the more they learn to earn. For Zhao and Cziko (2001), three conditions are mandatory for teachers to introduce ICT into their classrooms: teachers should believe in the effectiveness of technology, teachers should believe that the use of technology will not cause any disturbances, and finally teachers should believe that they have control over technology. Only this way, teachers can fully enjoy and enrich the ICT experience for their students to be curious, innovative and resourceful.

\section{Conclusion}

In this study, there has been a serious attempt to investigate the significance and efficacy of ICT- based instruction higher education and more specifically at the FSTT, as well as the challenges imposed by this new educational paradigm. According to the findings, a plethora of research participants were not satisfied with the outcomes of technology adoption amid COVID-19; primarily with respect to logistics. Students found multimedia-based education difficult as there was no prior training or needs analysis carried out. However, the research participants generally expressed positive attitudes toward the use of ICT in the EFL classroom, especially if it is properly and seamlessly handled and introduced. Teachers are more challenged now as the success of the teaching/learning task greatly depends on mindful choices of course content and technological maturity that will enable both students and educators to achieve success despite logistic and technical barriers. ICT in higher education can solely be effective and productive when lessons are consciously designed in congruency with learners' needs and multiple intelligences. In a nutshell, one can state that technology must be incorporated during planning and curriculum development in order to implement it easily and efficiently. To genuinely create a healthy and dynamic web environment requires from all stakeholders to actively participate in research and encourage more interactivity between learners and machines via and easy and instructional learning software. Online-based education can be a very promising and efficacious alternative to conventional teaching when it is well employed by education practitioners. Instrumental use of learner-centered tools that work emphatically to maximize interaction and participation leads to develop learners' autonomy and reasoning. In virtual settings, teachers are not the center of the teaching/learning process anymore; students and teachers rather work together in a linear way to accomplish tasks and attain 
objectives. Likewise, students tend to opt for non- conventional ways of learning for its flexibility and practicability in course instruction. Students find themselves autonomous and self-governed when it comes to seeking information and raising topics for discussion and debate. Moreover, learners feel more comfortable with videos and web-based learning because they are not restricted with time and space as they can interact with their teachers and classmates at any time and from different parts of the globe. Thus, ICTbased education has proven to be inevitable and beneficial in maintaining an engaging environment where both students and teachers are the building block of an effective and integral educational process.

\subsection{Further work}

Future studies and research should potentially emphasize more effective ways to surmount the barriers of ICT integration into higher education in Morocco. There should be more ICT leadership and innovative teaching methods of using technology other than flipped classroom and blended learning.

\section{Acknowledgements}

I would like to thank 1st year Master students (Computer Science and Coastal Sciences: Multidisciplinary Approach) at the Faculty of Sciences and Technologies in Tangier for their participation in the online questionnaire survey.

Funding: This study was not funded in any shape or form by any party.

\section{References}

Al-Oteawi, S. (2002). The perceptions of Administrators and teachers in utilizing information technology in instruction, administrative work, technology planning and staff development in Saudi Arabia. Doctoral Dissertation, Ohio University.

Arsham, H. (2002). Impact of the internet on learning and teaching. https://www.researchgate.net/publication/234635927. Accessed on $22 / 10 / 2020$.

Bachiri, H., \& Sahli, R. (2020). The Need of Distance Learning in the Wake of COVID-19 in Morocco: International Journal of Language and Literary Studies, 2(3), 240-256. https://doi.org/10.36892/ijlls.v2i3.326.

Bachiri, H., \& Tribak, O. (2020). The Role of ICT in the Teaching of Productive Skills in English during COVID-19: Teachers' Perceptions and Obstacles. Linguistic Forum -A Journal of Linguistics, 2(2), 35-44. https://linguisticforum.com/index.php/ling/article/view/47.

Berner, J. E. (2003). A study of factors that may influence faculty in selected schools of education in the Common wealth of Virginia to adopt computers in the classroom. Doctoral Dissertation, George Mason University. Pro Quest Digital Dissertations (UMI No. AAT 3090718).

Bingimlas, K. A. (2009). Barriers to the successful integration of ICT in teaching and learning environment: A review of the literature.

Bordbar, F. (2010). English teachers' attitudes toward computer-assisted language learning. International Journal of Language Studies, 4(3), $27-54$.

Bruniges, M. (2003). Developing performance indicators for ICT use in education: Australia's experience. Australian Council for Educational Research (ACER), 2011, University Experience Survey Design.

Daniels, J. (2002). Forward. Information and Communication Technology in education: A curriculum for schools and programs for teacher development; Paris, France: UNESCO.

Davis, B., \& Shade, D. (1999). Integrating technology into the early childhood classroom: The case of literacy learning (pp. 221- 254) Information technology in childhood education annual.

Demirci, A. (2009). How do teachers Approach New Technologies: Geography Teachers' Attitudes towards Geographic Information Systems (GIS). European journal of Educational Studies, Vol. 1, n .1.

Ennaji, M. (1998). Using technology as a teaching material. Paper presented at the 18th Annual Conference of the Moroccan Association of Teachers of English (MATE), Salé, Morocco.

Gardiner, L. (1993). Using hypermedia to turn university teaching inside out. Verbo-visual literacy: Understanding and applying new educational communication media technologies. Selected Readings from a Symposium of the International Visual Association (pp. 65-72). Delphi: Greece.

GENIE Directorate. (2012). Programme GENIE: Guide de Formateur. Module PDPTICE 2012. MEN.

Hamidi, F., Meshkat, M., Rezaee, M., \& Jafari, M. (2011). Information technology in education. Procedia Computer Science, 3 , $369-373$.

Hew., \& Thomas, B. (2007). Integrating technology into K-12 teaching and learning: Current knowledge gaps and recommendations for future research. Journal of Educational Technology, Research and Development, 55(3), 223-252.

Hussain, A., Morgan, S., \& Al-Jumeily, D. (2011). How does ICT affect teaching and learning with school education? In Developments in E- Systems Engineering (De SE), p. 250-254, IEEE.

Hutchison, A., \& Reinking, D. (2011). Teachers' perceptions of integrating information and communication technologies into literacy instruction: A national survey in the United States. Reading Research Quarterly, 312-333.

ITU, (2012). ICT Adoption and Prospects in the Arab Region. International Telecommunication Union: Geneva, Switzerland.

John, P. D., \& Sutherland, R. (2004). Teaching and learning with ICT: new technology, new pedagogy? Education, Communication \& Information, 4(1), 101107.

Jung, I. (2005). ICT-pedagogy integration in teacher training: Application cases worldwide. Journal of Educational Technology and Society, $8(2), 94-111$.

Kirkpatrick, D. L., \& Kirkpatrick, J. (2006). Evaluating training programs: The four levels. Williston: Berrett-Koehler. 
Kirkwood, A. (2008). Getting it from the Web: why and how online resources are used by independent undergraduate learners. Journal of Computer Assisted Learning, 24(5), 372-382.

Knezek, G., \& Christensen, R. (2002). Impact of New Information Technologies on Teachers and Students. Education and Information Technologies, 7(4), 369-376.

Kopinska, M. (2013). New technologies in foreign language classroom: The role of attitudes. The $6^{\text {th }}$ edition of the ICT for Language Learning Conference.

Lefebvre, S., Deaudelin, D., \& Loiselle, J. (2006). ICT implementation stages of primary school teachers: The practices and conceptions of teaching and learning. Paper presented at the Australian Association for Research in Education National Conference, Adelaide, Australia.

Naaim, E. H. (2015). Are Moroccan students enthusiastic about the use of technology in the classroom? Morocco World News (January 4th): n/a (Available at: https://www.moroccoworldnews.com/2015/01/148772/are-moroccan-students-enthusiastic-about-useof-technology-in-the-classroom/; Last accessed: 25 January, 2017).

Olasile, B. A., \& Emrah. S. (2020). Covid-19 pandemic and online learning: the challenges and opportunities, Interactive Learning Environments. DOI: 10.1080/10494820.2020.1813180.

Pelgrum, W. J., \& Law, N. (2001). Obstacles to the integration of ICT in education: results from a worldwide educational assessment. Computers \& Education, 37, 136-178.

Salehi, H., \& Salehi Z. (2012). Integration of ICT in language teaching: Challenges and barriers.3rd International Conference on eEducation, e-Business, e-Management and e- Learning IPEDRvol.27 IACSIT Press, Singapore.

Shockley, B. (2014). The Case for Online Education, Forbes Magazine, Forbes. 30 July 2012. Retrieved April 8, 2014. https://www.forbes.com/sites/ciocentral/2012/07/30/ the-case-for-online-education/\#109d955170b7.

Soussi, K. (2015). ICT and language teaching in the Moroccan EFL classroom: Perceptions, obstacles and strategies. International Journal of Science and Research, 4(7), 839-843

Summers, M. (1990). New student teachers and computers: an investigation of experiences and feelings. Educational Review, 42(3), 261271.

United Nations. Transforming Our World: The 2030 Agenda for Sustainable Development; A/RES/70/1; UNITED NATIONS: New York, NY, USA, 2015. Available online: https://sustainabledevelopment.un.org/content/documents/21252030\%20Agenda\%20for\%20Sustainable\%20Development\%20 web.pdf (accessed on 29 July 2020).

Yusuf, M. O. (2005). Information and communication education: Analyzing the Nigerian national policy for information technology. International Education Journal, 6(3), p; 316-321.

Zhao, Y., \& Cziko, G. A. (2001). Teacher adoption of technology: a perceptual control theory perspective, Journal for Technology and Teacher Education 9(1), p. 5-30. 